\title{
Remote sensing of Trichodesmium spp. mats in the western tropical South Pacific
}

\author{
Guillaume Rousset $^{1}$, Florian De Boissieu ${ }^{2}$, Christophe E. Menkes ${ }^{3}$, Jérôme Lefèvre ${ }^{4}$, Robert Frouin ${ }^{5}$, \\ Martine Rodier $^{6}$, Vincent Ridoux ${ }^{7,8}$, Sophie Laran ${ }^{7}$, Sophie Bonnet ${ }^{9}$, and Cécile Dupouy ${ }^{9}$ \\ ${ }^{1}$ IRD (Institut de Recherche pour le Développement), UMR ESPACE DEV, Nouméa, New Caledonia \\ ${ }^{2}$ Institut national de recherche en sciences et technologies pour l'environnement et l'agriculture (IRSTEA), \\ UMR TETIS, Montpellier, France \\ ${ }^{3}$ IRD-Sorbonne Universités (UPMC, Université Paris 06)-CNRS-MNHN, Laboratoire d'Océanographie et du Climat: \\ Expérimentations et Approches Numériques (LOCEAN), IRD Nouméa BP A5, 98848 Nouméa CEDEX, New Caledonia \\ ${ }^{4}$ IRD Nouméa, Laboratoire d'Etudes en Géophysique et Océanographie Spatiales (LEGOS), Nouméa, New Caledonia \\ ${ }^{5}$ Scripps Institution of Oceanography, University of California San Diego, La Jolla, CA 92093-0224, USA \\ ${ }^{6}$ EIO (Ecosystèmes Insulaires Océaniens), Institut de Recherche pour le Développement-Université de la Polynésie \\ Française-Institut Malarmé-Ifremer, Papeete, French Polynesia \\ ${ }^{7}$ Observatoire Pelagis, UMS3462, Université de la Rochelle/CNRS, La Rochelle, France \\ ${ }^{8}$ Centre d'Etude de Chizé, UMR7273 - CNRS- Université de La Rochelle, 2 Rue Olympe de Gouges, \\ 17000 La Rochelle, France \\ ${ }^{9}$ Aix Marseille Université-CNRS-INSU, IRD, Mediterranean Institute of Oceanography (MIO), UM110, \\ IRD Nouméa, BP A5, 98848 Nouméa CEDEX, New Caledonia
}

Correspondence: Guillaume Rousset (guillaume.rousset@ird.fr)

Received: 31 December 2017 - Discussion started: 9 January 2018

Revised: 24 July 2018 - Accepted: 26 July 2018 - Published: 29 August 2018

\begin{abstract}
Trichodesmium is the major nitrogen-fixing species in the western tropical South Pacific (WTSP) region, a hot spot of diazotrophy. Due to the paucity of in situ observations, remote-sensing methods for detecting Trichodesmium presence on a large scale have been investigated to assess the regional-to-global impact of this organism on primary production and carbon cycling. A number of algorithms have been developed to identify Trichodesmium surface blooms from space, but determining with confidence their accuracy has been difficult, chiefly because of the scarcity of sea-truth information at the time of satellite overpass. Here, we use a series of new cruises as well as airborne surveys over the WTSP to evaluate their ability to detect Trichodesmium surface blooms in the satellite imagery. The evaluation, performed on MODIS data at $250 \mathrm{~m}$ and $1 \mathrm{~km}$ resolution acquired over the region, shows limitations due to spatial resolution, clouds, and atmospheric correction. A new satellite-based algorithm is designed to alleviate some of these limitations, by exploiting optimally spectral fea-
\end{abstract}

tures in the atmospherically corrected reflectance at 531, 645, 678,748 , and $869 \mathrm{~nm}$. This algorithm outperforms former ones near clouds, limiting false positive detection and allowing regional-scale automation. Compared with observations, $80 \%$ of the detected mats are within a $2 \mathrm{~km}$ range, demonstrating the good statistical skill of the new algorithm. Application to MODIS imagery acquired during the FebruaryMarch 2015 OUTPACE campaign reveals the presence of surface blooms northwest and east of New Caledonia and near $20^{\circ} \mathrm{S}-172^{\circ} \mathrm{W}$ in qualitative agreement with measured nitrogen fixation rates. Improving Trichodesmium detection requires measuring ocean color at higher spectral and spatial $(<250 \mathrm{~m})$ resolution than MODIS, taking into account environment properties (e.g., wind, sea surface temperature), fluorescence, and spatial structure of filaments, and a better understanding of Trichodesmium dynamics, including aggregation processes to generate surface mats. Such sub-mesoscale aggregation processes for Trichodesmium are yet to be understood. 


\section{Introduction}

The western tropical South Pacific (WTSP) is a low nutrient, low chlorophyll (LNLC) region, harboring surface nitrate concentrations close to detection limits of standard analytical methods and limiting for the growth of the majority of phytoplankton species (Le Borgne et al., 2011). This lack of inorganic nitrogen favors the growth of dinitrogen $\left(\mathrm{N}_{2}\right.$ )-fixing organisms (or diazotrophs), which have the ability to use the inexhaustible pool of $\mathrm{N}_{2}$ dissolved in seawater and convert it into bioavailable ammonia. Several studies have reported high $\mathrm{N}_{2}$ fixation rates in the WTSP (Berthelot et al., 2017; Bonnet et al., 2009; Bonnet et al., 2015; Garcia et al., 2007), which has recently been identified as a hot spot of $\mathrm{N}_{2}$ fixation (Bonnet et al., 2017). During austral summer conditions, $\mathrm{N}_{2}$ fixation supports nearly all new primary production and organic matter export (Caffin et al., 2018; Knapp et al., 2018) as nitrate diffusion across the thermocline and atmospheric sources of $\mathrm{N}$ are $<10 \%$ of new $\mathrm{N}$ inputs. The cyanobacterium Trichodesmium is one of the most abundant diazotrophs in our oceans (Capone, 1997; Luo et al., 2012) and in the WTSP in particular (Tenório et al., 2018; Stenegren et al., 2018). Cellspecific $\mathrm{N}_{2}$ fixation measurements recently conducted in the WTSP have revealed Trichodesmium as the major $\mathrm{N}_{2}$ fixing organism, accounting for $>60 \%$ of total $\mathrm{N}_{2}$ fixation (Bonnet et al., 2018). One of the characteristics of Trichodesmium is the presence of gas vesicles, which provide buoyancy (van Baalen and Brown, 1969; Villareal and Carpenter, 2003) and help maintain this cyanobacterium in the upper ocean surface. Trichodesmium cells are aggregated and form long chains called trichomes. Trichomes then can gather into colonies called "puffs" or "tuffs", and these colonies can aggregate at the surface of the water and form large mats that can extend for miles. They had already been observed during James Cook's and Charles Darwin's expeditions. During the southern austral summer, Trichodesmium blooms have long been detected by satellites in the region, mostly around New Caledonia and Vanuatu (Dupouy et al., 2000, 2011), and later confirmed by microscopic enumerations (Shiozaki et al., 2014).

Identifying the occurrence and the spatial distribution of Trichodesmium blooms and mats is of primary importance to assess their regional contribution to primary production and biogeochemical cycles. However, because of their paucity, scientific cruises alone are not sufficient to achieve such a goal, and remote sensing completed by sea observations of mats appears as the unique alternative for assessing its global impact. By using Trichodesmium spectral characteristics, among which are pigment absorption due to phycoerythrin (PE) between 490 and $570 \mathrm{~nm}$, absorption/scattering increase in the red-near infrared (NIR), and particle backscattering (Subramaniam et al., 1999a, b; Hu et al., 2010), several empirical bio-optical algorithms have been developed to detect Trichodesmium blooms from various satellite sensors. They are extensively documented in Blondeau-Patissier et al. (2014) and Mckinna (2015). Former algorithms are classification schemes using thresholds applied to reflectances in the blue-green (440-550) range, like those proposed by Subramaniam et al. (2002) and Dupouy et al. (2011). They were designed using Sea-viewing Wide Field-of-view Sensor (SeaWiFS) observations. Using spectral features in Moderate Resolution Imaging Spectroradiometer (MODIS) Aqua observations at $250 \mathrm{~m}$ in the redNIR, McKinna et al. (2011) elaborated a simple reflectance classification algorithm to detect dense Trichodesmium surface aggregation. By providing an operational floating algae index (FAI), Hu et al. (2010) also demonstrated the potential for using the red-edge effect, that is, the increasing absorption in the red (620-700) and scattering in the NIR (beyond 700) region of the spectrum due to floating algae. Using Medium Resolution Imaging Spectrometer (MERIS) observations in the red-NIR band, Gower et al. (2014) provided a similar index of Trichodesmium surface slicks. In their Trichodesmium bio-optical model, Westberry et al. (2005) used specific inherent optical properties (Trichodesmium-specific absorption and backscattering parameters) to estimate Trichodesmium biomass from SeaWiFS reflectances.

The application of these algorithms to MODIS imagery revealed several issues, some of which were raised and discussed in the aforementioned articles. For example, the red edge over Trichodesmium mats can lead to controversial results since atmospheric correction for aerosols is based on information at similar wavelengths (Hu et al., 2010). Sampling effects are also exacerbated due to the occurrence of clouds in the WTSP since the blooming period of Trichodesmium (mainly November to March; Dupouy et al., 2011) coincides with the cloudiest period of the South Pacific Convergence Zone, making it difficult to identify coincident in situ mats in satellite imagery. Moreover, because Trichodesmium mats are narrow ( $\backsim 50 \mathrm{~m}$ typically), the suitability of MODIS visible-NIR spatial resolution to detect such surface aggregations is questionable.

The aim of this study is to provide a systematic detection of Trichodesmium blooms in the vast WTSP ocean between latitudes 26 and $10^{\circ} \mathrm{S}$ and longitudes 155 and $190^{\circ} \mathrm{E}$, building on previously published algorithms and using marine reflectances measured by MODIS onboard Aqua. To evaluate the detection performance, a large database of historical mat observations in this region was created and updated with recent datasets and particularly the Oligotrophy to UlTra-oligotrophy PACific Experiment (OUTPACE) cruise of March-April 2015 (Moutin et al., 2017). As a consequence of improvements in MODIS Collection 6 calibrations and algorithm updates for aerosol and cloud screening (Casey et al., 2017), Trichodesmium detection algorithms developed with previous collections had to be adapted whenever possible. From this experience, a new algorithm less prone to contamination by clouds emerged, combining methods to detect Trichodesmium blooms from algorithms by 
McKinna et al. (2011) and Hu et al. (2010) and was evaluated using high-resolution MODIS imagery. The paper is organized as follows. In Sect. 2 in situ and satellite data used in this study are presented. In Sect. 3 methods to extract Trichodesmium spectral signature and their limitations are described, and details are provided about the former detection algorithms of Hu et al. (2010) and McKinna et al. (2011), adapted for this study, as well as the newly developed algorithm. In Sect. 4 these algorithms are compared, and the proposed algorithm is evaluated along the OUTPACE cruise transect. In Sect. 5 the new algorithm performance is discussed. In Sect. 6 the conclusions of the study are drawn and perspectives are provided for future work.

\section{Material}

\subsection{In situ observations}

The in situ data used to train and test the Trichodesmium detection algorithm are a combination of three datasets, providing data in the acquisition period of MODIS Aqua or Terra missions (March 2000-present). The first dataset includes Trichodesmium mat observations published in Dupouy et al. (2011). These observations were made between 1998 and 2010, from aircraft, French Navy ships, research vessels (e.g., R/V Alis), and ships of opportunity. Some of these visual observations were confirmed by water samples analyzed with photomicrographs confirming the abundant presence of Trichodesmium (Dupouy et al., 2011). The second dataset includes airborne visual observations also gathered in December 2014 in the vicinity of New Caledonia during the "REcensement des Mammifères marins et autre Mégafaune pélagique par Observation Aérienne" (REMMOA) program (Laran et al., 2016). This second dataset provides a large number of Trichodesmium mat observations along numerous and repetitive transects, which is most favorable for satellite data validation. In total, the database created from the compilation of these two datasets contains 507 open-ocean observations in the region $15-25^{\circ} \mathrm{S}, 155$ $180^{\circ} \mathrm{E}$ (Fig. 1). It is referred to as the observation base of Trichodesmium (OBT) in the following and used mainly for algorithm training.

A third dataset was obtained along a latitudinal transect around $20^{\circ} \mathrm{S}$ carried out during the OUTPACE scientific cruise (Moutin et al., 2017) in the region $160^{\circ} \mathrm{E}-160^{\circ} \mathrm{W}$ from 23 February to 1 April 2015. Seawater samples were collected for Trichodesmium identification and estimation by quantitative polymerase chain reaction (PCR), a molecular method described in Stenegren et al. (2018), microscopic counts at selected stations (Mathieu Caffin, personal communication, 2017), and $\mathrm{N}_{2}$ fixation rates as described in Bonnet et al. (2018). Moreover, Trichodesmium abundance from the Underwater Vision Profiler 5 (UVP5; Picheral et al., 2010), calibrated on trichome concentration from pigment

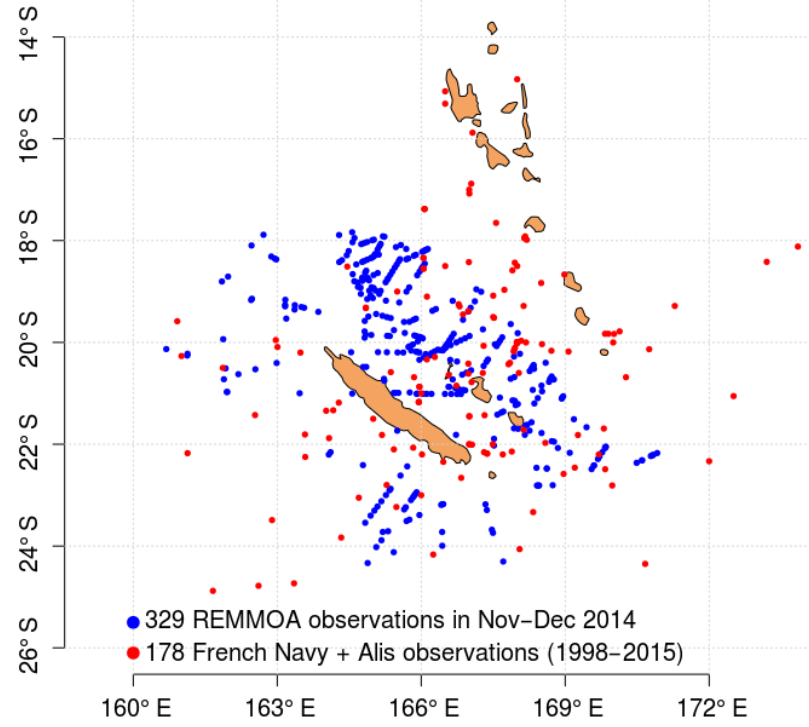

Figure 1. Map of in situ (visual) observations of Trichodesmium mats gathered in the studied region.

algorithms and on visual counts of surface samples at every station, allowed one to describe the Trichodesmium distribution along the transect (Dupouy et al., 2018).

\subsection{Satellite data}

Marine reflectances from MODIS Aqua and Terra Collection 6 coinciding in time and space with the OBT database and the OUTPACE campaign are used in this study. Level 1A observations were downloaded from NASA's Goddard Space Flight Center (https://oceandata.sci.gsfc.nasa.gov/, last access: 13 August 2018) and processed with SeaDAS v7.0.2 to produce Level 2 reflectances at $250 \mathrm{~m}$ and $1 \mathrm{~km}$ resolution. SeaDAS v7.0.2 default values were applied during this processing for atmospheric correction failure, land, sun glint, very high or saturated radiance, sensor viewing zenith angle exceedance threshold, stray light contamination, and cloud contamination. Satellite observations with a proportion of valid pixels lower than $40 \%$ within the $0.5^{\circ}$ searching radius around each in situ observation were screened out.

MODIS atmospherically corrected (aerosol + Rayleigh) remote-sensing reflectances $\left(R_{\mathrm{rS}}\right)$ in the visible, NIR, and short-wavelength infrared (SWIR) ranges were used at different resolutions: $250 \mathrm{~m}$ for bands $1(645 \mathrm{~nm})$ and $2(859 \mathrm{~nm})$, $500 \mathrm{~m}$ (bands 3-7, visible and SWIR land- and clouddedicated bands), and $1 \mathrm{~km}$ (bands $8-16$ ). Bands 8 to 16 are dedicated to ocean color (Table 1), but the information in high-resolution bands located in the visible-NIR region is also used to track floating blooms. To evaluate the influence of resolution on detection performances, Level 2 remotesensing data were produced at both $250 \mathrm{~m}$ and $1 \mathrm{~km}$ resolutions, with interpolation of $500 \mathrm{~m}$ and $1 \mathrm{~km}$ data and aggre- 
Table 1. Specification of the first 13 MODIS channels, including primary use, central wavelength, bandwidth, and spatial resolution; http: //eoweb.dlr.de:8080/short_guide/D-MODIS.html (last access: 13 August 2018).

\begin{tabular}{lrrrrl}
\hline & $\begin{array}{r}\text { Central } \\
\text { wavelength }(\mathrm{nm})\end{array}$ & $\begin{array}{r}\text { MODIS band } \\
\text { number }\end{array}$ & $\begin{array}{r}\text { Spectral coverage } \\
\text { and bandwidth (nm) }\end{array}$ & $\begin{array}{r}\text { Spatial } \\
\text { resolution }\end{array}$ & $\begin{array}{l}\text { Key use } \\
\text { in SeaDAS }\end{array}$ \\
\hline Visible & 8 & $405-420(15)$ & 1000 & Ocean color, phytoplankton \\
& 443 & 9 & $438-448(10)$ & 1000 & Ocean color, phytoplankton \\
& 469 & 3 & $459-479(20)$ & 500 & Land/vegetation \\
& 488 & 10 & $483-493(10)$ & 1000 & Ocean color, phytoplankton \\
531 & 11 & $526-536(10)$ & 1000 & Ocean color, phytoplankton \\
& 12 & $542-552(10)$ & 1000 & Ocean color, phytoplankton \\
& 547 & $620-670(20)$ & 500 & Land/vegetation \\
645 & 1 & $662-670(50)$ & 250 & Land, cloud, aerosol \\
667 & 13 & $662-672(10)$ & 1000 & Ocean color, phytoplankton \\
& 14 & $673-683(10)$ & 1000 & Chlorophyll fluorescence \\
\hline Near infrared & 15 & $743-753(10)$ & 1000 & Ocean color, red edge, atmospheric correction \\
& 748 & 2 & $841-876(35)$ & 250 & Land, cloud, aerosol \\
& 859 & $862-877(15)$ & 1000 & Ocean color, red edge, atmospheric correction \\
\hline
\end{tabular}

gation of 250 and $500 \mathrm{~m}$ resolution data, respectively. The consequences of this processing are discussed in Section 5.

The aerosol correction was carried out with the standard Gordon and Wang (1994) method since the study was conducted in the open ocean (Case 1 waters). For reasons detailed in next section, this type of correction is not appropriate in the presence of strong floating algae concentrations. Therefore, Rayleigh-corrected-only reflectances $\left(R_{\mathrm{rc}}\right)$ were computed in addition to $R_{\mathrm{rs}}$ in Level 2 outputs.

\section{Methods}

\subsection{Motivation in using Rayleigh-corrected reflectance $\left(R_{\text {rc }}\right)$ in bio-optic algorithms for floating blooms}

The atmospheric correction scheme of Gordon and Wang (1994) utilizes a pair of NIR bands at 748 and $869 \mathrm{~nm}$. Spectral differences in the two NIR bands are used to select the most probable aerosol model, allowing an estimation of the aerosol effects in the visible range. The aerosol contamination is then removed from the top-ofatmosphere (TOA) signal after Rayleigh scattering correction to yield water-leaving radiance, therefore $R_{\mathrm{rs}}$, in the visible. But to retrieve the aerosol model over Case 1 waters, the Gordon and Wang (1994) method relies on the assumption that optical constituents have negligible contribution to water-leaving radiances in the NIR region. Over floating mats, this assumption does not hold due to red-edge effects, and the atmospheric correction may give erroneous (i.e., too low and even negative) values of $R_{\mathrm{rs}}$ as detailed in Hu et al. (2010). For this reason, $R_{\mathrm{rc}}$ was preferred in floating algal bloom concentration detection algorithms, as performed with the FAI in Hu et al. (2010) or with the Maximum Chlorophyll Index (MCI) in Gower et al. (2008). This issue is illustrated in Fig. 2, which presents a MODIS Aqua image of the Australian coast acquired just after a period of heavy rain that led to a massive Trichodesmium bloom. Fortunately, this bloom was also documented through field studies (McKinna et al., 2011). Figure 2a shows the "true color" image obtained using a combination of $R_{\mathrm{rc}}$ at 469 , 555 , and $645 \mathrm{~nm}$. On this image, large visible Trichodesmium mats distributed over a vast area can be seen. Figure $2 b$ displays the SeaDAS-derived aerosol optical thickness (AOT) at $555 \mathrm{~nm}$, an indicator of the aerosol load in the atmosphere. The high AOT values match the filamentous spatial structure noticed in the true color image. However, this structure is more likely to be floating material as the patterns are very thin and do not seem to be driven by wind. Moreover, several patches within this structure are flagged as cloud in the center (grey patches in Fig. 2b), although the true color image does not indicate the presence of clouds in this particular area. The misclassification of marine to cloudy pixel is a failure of the cloud detection algorithm, resulting from high water-leaving signal in the NIR bands exceeding the albedo threshold of $2.7 \%$ (Wang and Shi, 2005). Figure 2c shows the chlorophyll concentration ( $\mathrm{Chl} a$ ) estimated according to the OC3 algorithm when Chl $a$ retrievals are above $0.2 \mathrm{mg} \mathrm{m}^{-3}$ and to the ocean color index (OCI) algorithm when they are below (Hu et al., 2012). Chl $a$ decreases systematically, even falling to zero, in the vicinity of the Trichodesmium patches, although the real concentrations are certainly larger at the core of the mats than at their periphery. In addition to biomass underestimation, the spectral miscorrection may reduce the performance of reflectance classification schemes, like those based on simple reflectance thresholds or using reflectance ratios in the blue-green range. Prior to using such classification schemes, the spectral signature of Trichodesmium mats using MODIS $R_{\mathrm{rs}}$ and $R_{\mathrm{rc}}$ need to be further investigated (see below). 


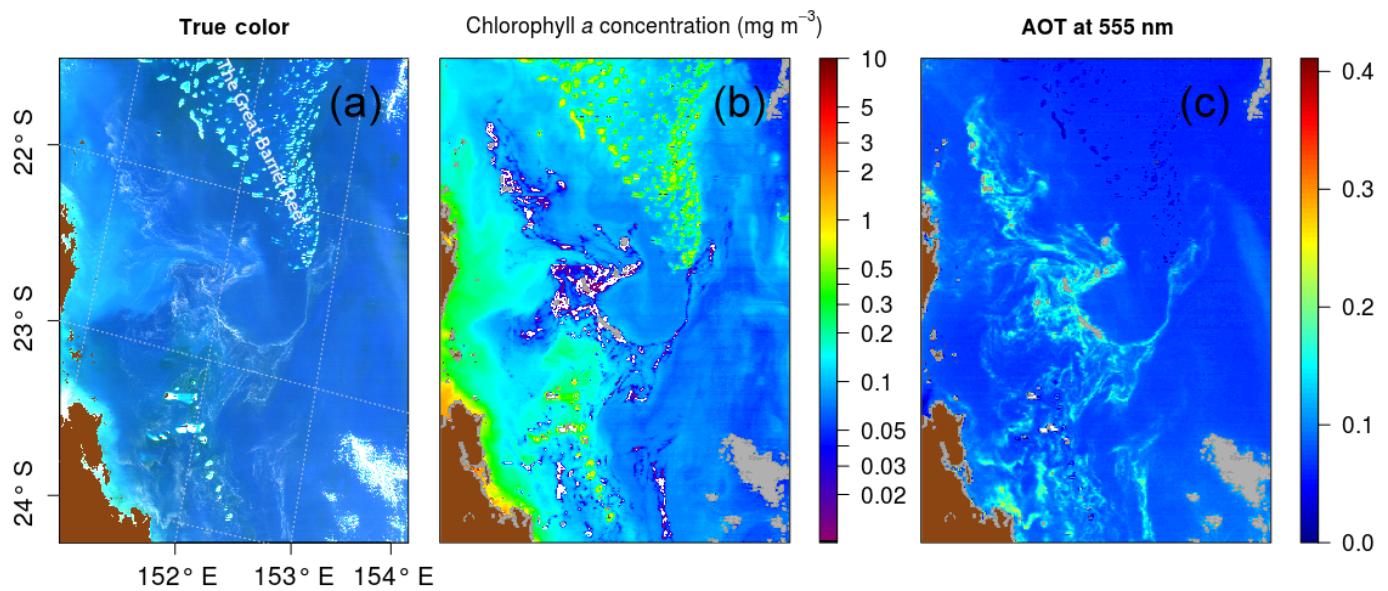

Figure 2. MODIS Aqua tile A2007290.0355 used in McKinna et al. (2011): (a) RGB (red, green, blue) image from $R_{\mathrm{rc}}$ generated with $R=645, G=555$, and $B=469 \mathrm{~nm}$ computed using the formulae $0.29319407+0.45585 \times \operatorname{atan}\left(50 \times\left(R_{\mathrm{rc}}\right)-0.015\right)$; (b) aerosol optical thickness at $555 \mathrm{~nm}$ derived using the NIR atmospheric correction algorithm by Gordon and Wang (1994); (c) chlorophyll concentration product computed from $R_{\mathrm{rs}}$ using OC3 and OCI (Hu et al., 2012). Cloud pixels are in grey and land pixels are in brown.

Table 2. Satellite image with in situ observations used to analyze Trichodesmium mat and adjacent spectra.

\begin{tabular}{|c|c|c|}
\hline Tiles & Date & Location \\
\hline A2002341.0255 & 7 December 2002 & East of New Caledonia \\
\hline A2004047.0230 & 16 February 2004 & Loyalty Islands \\
\hline A2004059.0255 & 28 February 2004 & East of New Caledonia \\
\hline A2014344.0245 & 10 December 2014 & $\begin{array}{l}\text { Loyalty Islands } \\
\text { (east of Ouvéa) }\end{array}$ \\
\hline A2014351.0255 & 17 December 2014 & Northeast of New Caledonia \\
\hline A2014353.0240 & 19 December 2014 & $\begin{array}{l}\text { Between Vanuatu } \\
\text { and New Caledonia }\end{array}$ \\
\hline
\end{tabular}

\subsection{Extraction of the spectral signature of mats}

With the persistent cloud cover in the region, the number of strict coincidences of in situ observations and cloud-free MODIS pixels with visible Trichodesmium mats is small. To extract the Trichodesmium spectral signature corresponding to the OBT, six tiles have been specifically selected (Table 2) and are used later on to test the different bio-optical algorithms designed to detect the Trichodesmium presence. These images have been chosen because they are relatively free of clouds, Trichodesmium mats are visible in the true color images, and they contain many "ground-truth" observations (Fig. 3).

The NASA Ocean Biology Processing Group method (Bailey and Werdell, 2006) to select matchups, i.e., average or nearest pixel, was used to find coincidences between in situ observations and clear MODIS satellite pixels. A total of 468 coincident MODIS Aqua pixels and OBT observations were found. After data screening, only 50 pairs remained, indicating that approximately $90 \%$ of in situ observations were not usable, primarily because of cloud cover. Once inspected,
19 MODIS Aqua spectra out of the 50 pixels exhibited Trichodesmium features similar to those documented in $\mathrm{Hu}$ et al. (2010) and McKinna et al. (2011). In order to increase the number of useful observations, the searching window was extended both in time (up to \pm 4 days), with the hypothesis that a bloom can last for $\sim 1$ week (e.g., Hegde et al., 2008), and spatially over $\pm 50 \mathrm{~km}$, i.e., $\backsim 200$ pixels at $250 \mathrm{~m}$ resolution. This spatial relaxation up to $\pm 50 \mathrm{~km}$ is motivated by considering a maximum drifting speed of $\backsim 10 \mathrm{~cm} \mathrm{~s}^{-1}$ for algae mats compatible with the observed surface drifts in that region (Rousselet et al., 2018; Cravatte et al., 2015). Also, some in situ observations close spatially and temporarily (in the same tile and at intervals of \pm 4 days) and increased our degree of confidence in identifying the filamentous patterns due to Trichodesmium.

After extending the searching window, a total of 1200 spectra were extracted. Spectra were labeled, based on information provided by the FAI (Hu, 2009) and the presence or absence of visible mats in the true color image. When the pixel coincides with a visible mat on the true color image and is characterized with high FAI but low Chl $a$, it is labeled Type $i$ : it is the signature of high algae concentration. Pixels in close proximity to Trichodesmium mats with low FAI and undetected mats in the true color image are labeled Type ii. This second type of pixels is expected to have a high number of Trichodesmium colonies although not aggregated, offering an opportunity to detect spectral features due to the presence of Trichodesmium pigments other than $\mathrm{Chl} a$.

\subsection{Robust spectral features over and near Trichodesmium mats}

Figure $4 \mathrm{~b}$ shows Type i average $R_{\mathrm{rc}}$ spectrum for $1 \mathrm{~km}$ resolution images. Compared to the blue water spectrum (see 


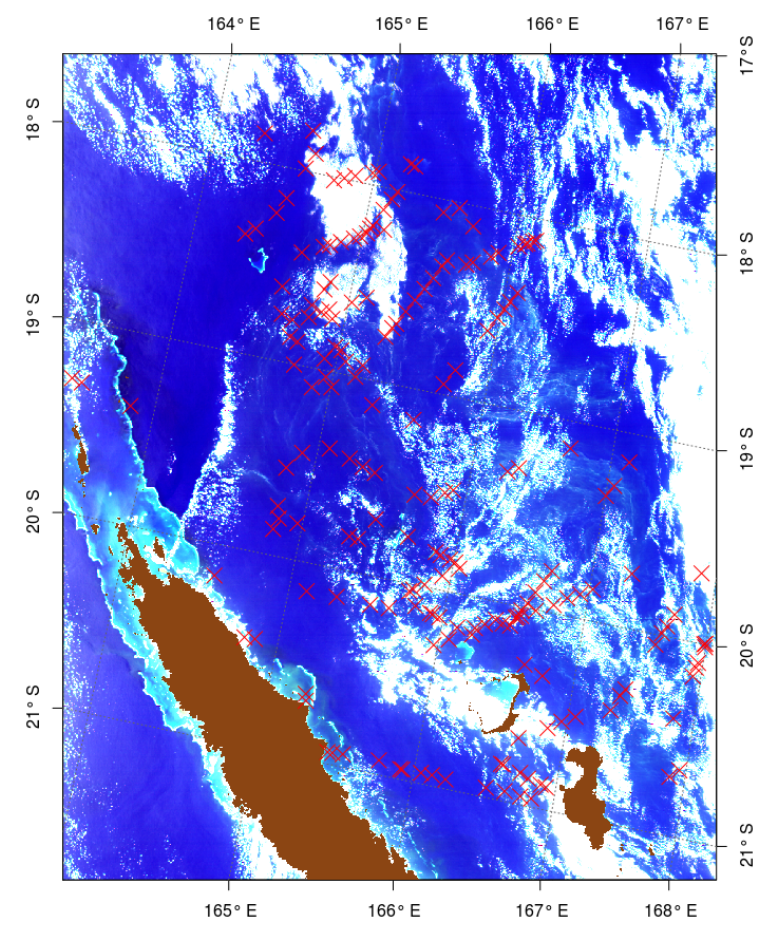

Figure 3. True color image of 17 December "2014A2014351.0255" for which in situ observations (red crosses) exist in the OBT database, and it was used for the test and adjustment of the different bio-optical algorithms.

blue curve) no Trichodesmium spectral feature could be detected in the visible and NIR spectral domain. The increase in $R_{\mathrm{rc}}$ beyond $700 \mathrm{~nm}$ indicates that, at low resolution, the red edge effect is weakly discernible over floating algae, contrasting with robust signals detected by McKinna et al. (2011) and $\mathrm{Hu}$ et al. (2010) using both hyperspectral and MODIS $250 \times 250 \mathrm{~m}$ observations over Trichodesmium mats. As suggested by these authors, spectral sensors with $1 \mathrm{~km}$ resolution are inappropriate to capture floating Trichodesmium due to negligible signal from discrete mats once mixed with adjacent water in $1 \times 1 \mathrm{~km}$ cells. The middle and bottom rows of Fig. 4 present $R_{\mathrm{rc}}$ and $R_{\mathrm{rs}}$ spectra interpolated to $250 \mathrm{~m}$ and partitioned in Type $\mathrm{i}$ and Type ii (middle row and bottom row, respectively). For Type i, it is noteworthy that the red edge signal is well captured in the NIR region at $859 \mathrm{~nm}$, a MODIS land band with true $250 \mathrm{~m}$ resolution, while in the 758 and $896 \mathrm{~nm}$ bands the derived signals using bilinear interpolation are still low. One can notice that, after application of the NIR atmospheric correction, the shape of the mean $R_{\mathrm{rs}}$ spectra remains similar to that of $R_{\mathrm{rc}}$, minus an offset in the visible region, corresponding to subtraction of the flawed aerosol contribution (compare Fig. $4 \mathrm{c}$ with Fig. 4d). Derived $R_{\mathrm{rs}}$ values at 748 and $869 \mathrm{~nm}$ are set to zero, as a result of the black pixel approximation.

For Type ii, the red-edge effect totally disappears from the true $250 \mathrm{~m}$ band at $859 \mathrm{~nm}$ and the derived baseline 758
$869 \mathrm{~nm}$ appears above $R_{\mathrm{rc}}$ (and $R_{\mathrm{rs}}$ ) at $859 \mathrm{~nm}$. Hu (2009) had already noticed this issue for pixels with strong spatial gradients in the NIR part of the spectrum. It is interpreted as a result of the bilinear interpolation of 758 and $869 \mathrm{~nm}$ bands from $1 \mathrm{~km}$ to $250 \mathrm{~m}$, using information from adjacent $1 \mathrm{~km}$ pixels.

Unfortunately, in the visible region, there is little useful information to capture Trichodesmium with $R_{\mathrm{rc}}$ (or $R_{\mathrm{rs}}$ ) spectra interpolated to $250 \mathrm{~m}$, in both Type i and Type ii situations. In Trichodesmium blooms, a release of dissolved colored substance was observed, as suggested by $\mathrm{Hu}$ et al. (2010) for coastal waters. For oligotrophic waters studied here, there was no such absorption in the blue region $(412 \mathrm{~nm})$ due to possible dissolved colored substances. Other characteristic features due to absorption maxima around 495 and $550 \mathrm{~nm}$ caused by the presence of phycourobilin and phycoerythrobilin, respectively (see Fig. 5 in Hu et al., 2010), are not seen using the 600 spectra-composite spectrum. Finally, the only robust spectral feature in the visible range is a minimum in $R_{\mathrm{rc}}$ (and $R_{\mathrm{rs}}$ ) occurring at $678 \mathrm{~nm}$, due to increasing reflectance beyond $700 \mathrm{~nm}$.

Interestingly, comparison between $R_{\mathrm{rc}}$ and $R_{\mathrm{rs}}$ shows that standard deviation error bars are much smaller for $R_{\mathrm{rc}}$ reflectances while the range of magnitudes in between wavelengths is larger. This is a significant argument for using $R_{\mathrm{rc}}$ instead of $R_{\mathrm{rs}}$, as it would lead to a better discrimination of Trichodesmium mat spectra against other spectra.

\subsection{Two published algorithms}

Among the existing Trichodesmium mat detection algorithms, only the McKinna et al. (2011) and Hu et al. (2010) ones were designed for the MODIS sensor and were tested in this study. The other algorithms were ignored as they were not adaptable to the MODIS sensor or would give erroneous results due to Chl $a$ misestimation over Trichodesmium mats.

The Trichodesmium mat detection algorithm of McKinna et al. (2011) is based on four criteria relative to the shape of $R_{\mathrm{rs}}$ (given in the Appendix $\mathrm{A}$ ). When applied to the same MODIS image (new collection) as the one used by McKinna et al. (2011), more pixels were discarded due to the fourth criterion, which eliminated pixels with negative normalized water-leaving radiance (nLw) at $555,645,678$, or $859 \mathrm{~nm}$. Indeed, the test of a negative $R_{\mathrm{rs}}$ value at $678 \mathrm{~nm}$ due to aerosol overcorrection excludes many pixels. Other atmospheric corrections, including that of Wang and Shi (2007) used by McKinna et al. (2011), have been applied with the same results. Skipping the fourth criterion of the algorithm allowed us to match the results of McKinna et al. (2011). Therefore, this modification was adopted for the present study and the algorithm is called McKinna modified in the following.

The Trichodesmium detection algorithm presented in $\mathrm{Hu}$ et al. (2010) is based on a two-step analysis of $R_{\mathrm{rc}}$ spectra. The first step captures floating algae with FAI. The second 


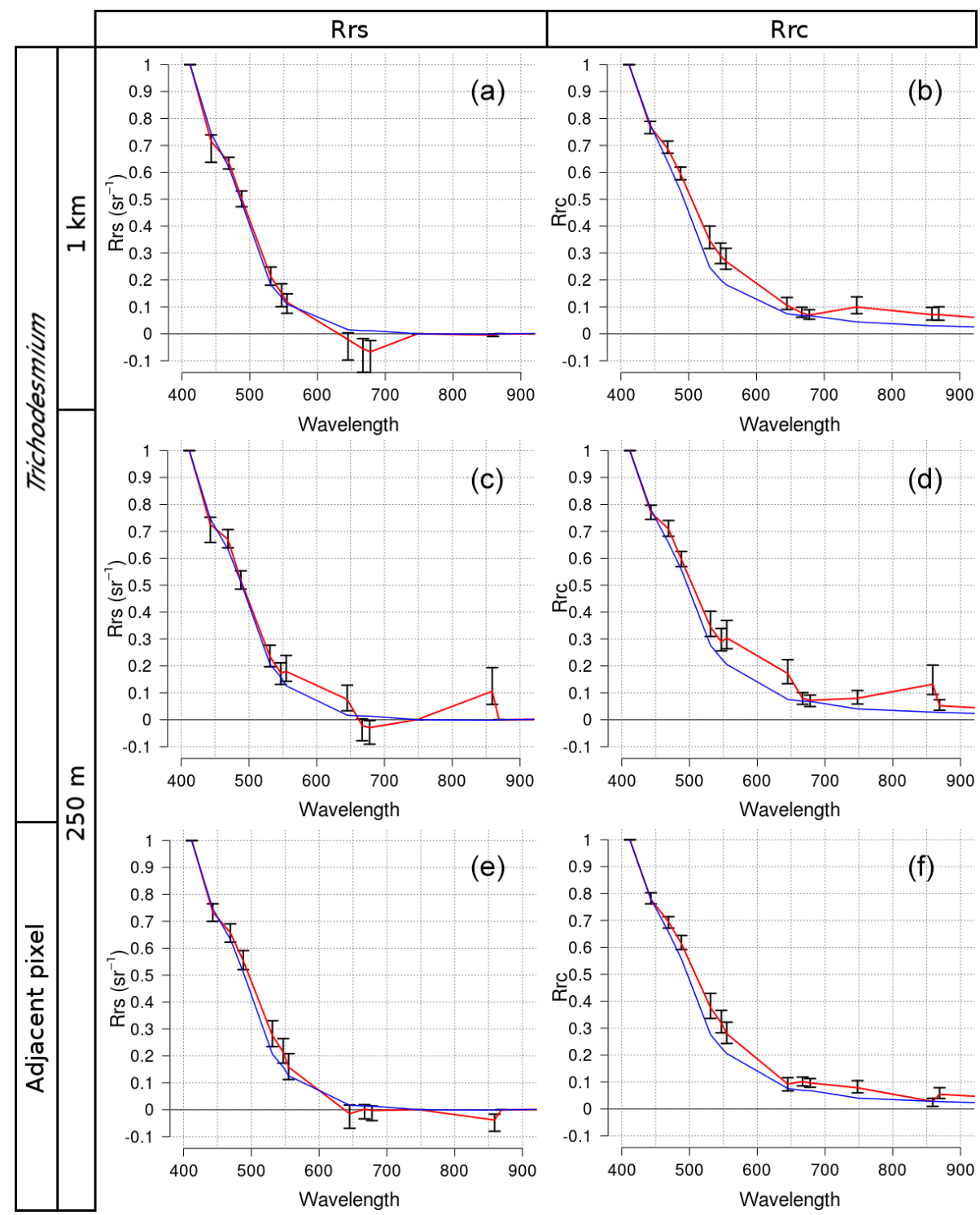

Figure 4. MODIS spectra of Trichodesmium mats $(\mathbf{a}, \mathbf{b}, \mathbf{c}, \mathbf{d})$ and adjacent areas $(\mathbf{e}, \mathbf{f})$ normalized by the maximum spectral value of all wavelengths, with pixel resolution at $1 \mathrm{~km}(\mathbf{a}, \mathbf{b})$ and $250 \mathrm{~m}(\mathbf{c}, \mathbf{d}, \mathbf{e}, \mathbf{f})$. Panels $(\mathbf{a}),(\mathbf{c})$, and (e) are $R_{\mathrm{rs}}$ reflectances. Panels $(\mathbf{b}),(\mathbf{d})$, and (f) are $R_{\mathrm{rc}}$ reflectances. The average is the red line and error bars are the standard deviation. The average of the water signal is the blue line.

step resolves the ambiguities between Trichodesmium and Sargassum by analyzing spectral features in the blue-green region. To overcome possible spectral influence due to inappropriate atmospheric correction, Hu et al. (2010) proposed a simple correction method based on the difference in $R_{\mathrm{rc}}$ spectra between a bloom and nearby algae-free region. After several tries on the data presented above, the second step was found to be sensitive to the choice of the algae-free region (not shown). Thus, the detection was made only by applying thresholds to FAI. After tuning, the best results were obtained when FAI was between 0 and 0.04 .

\subsection{New algorithm criteria}

Our criteria for detecting Trichodesmium mats were defined based on spectral characteristics of $R_{\mathrm{rs}}$ and $R_{\mathrm{rc}}$ (Fig. 4). Similar to the algorithms of $\mathrm{Hu}$ et al. (2010) and McKinna et al. (2011) (see Appendix), three criteria given in Eqs. (1)-(3) were defined to extract the typical spectrum shape of Trichodesmium. The first criterium (Eq. 1) takes advantage of the systematic negative $R_{\mathrm{rs}}$ values at $678 \mathrm{~nm}$ over strong Trichodesmium mat concentrations. All pixels with a negative $R_{\text {rs }}$ value at this wavelength have a high probability of being floating algae and thus Trichodesmium in this region. Moreover, this criterium can also be used to detect some artifacts, e.g., sun glint. 

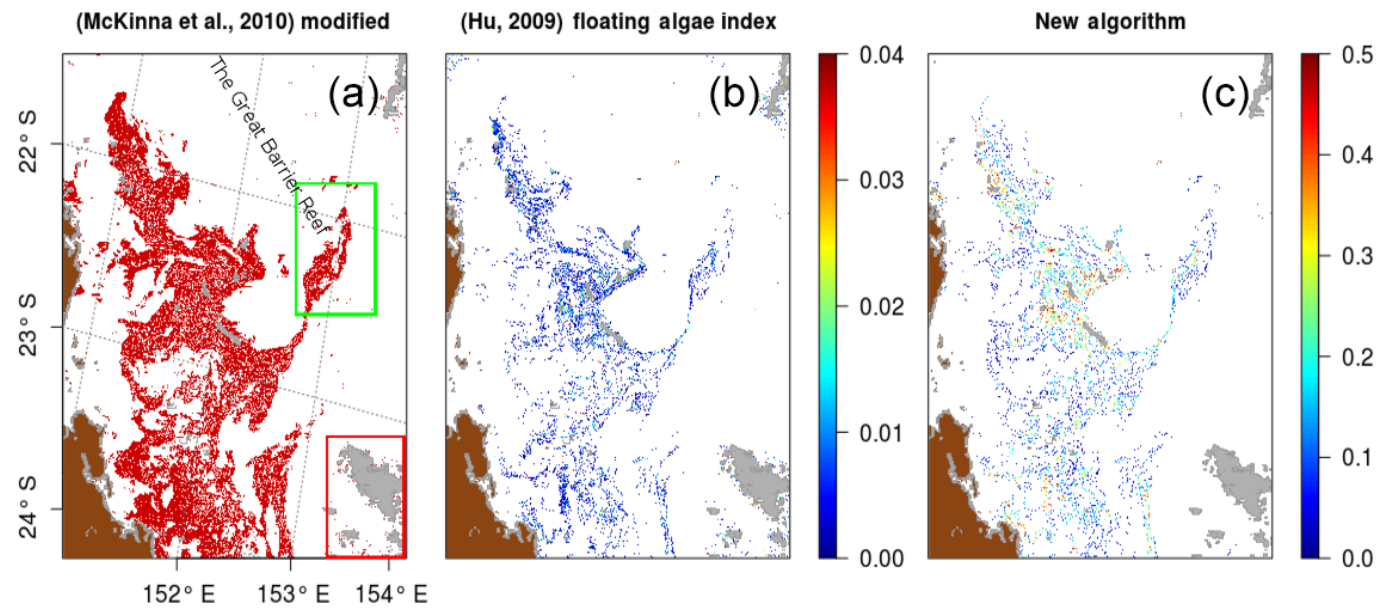

Figure 5. Trichodesmium mat detection results on MODIS tile "A2007290.0355". (a) Detected pixels with the McKinna modified algorithm in red; (b) FAI value of detected pixels with the FAI algorithm; (c) pixels detected with the new algorithm, and color represents the $R_{\mathrm{rs}}(678)$ absolute value of the detected pixels. Cloud pixels are in grey.

The second criterium (Eq. 2) is based on $R_{\mathrm{rc}}(748)$ and $R_{\mathrm{rc}}(859)$ to detect the spectral shape in the NIR associated with the surface Trichodesmium mats. The third criterium (Eq. 3) uses $R_{\mathrm{rc}}(645)$ and $R_{\mathrm{rc}}(531)$ to resolve ambiguities between Trichodesmium mats and incorrectly selected pixels after processing with the previous criteria, the misdetections occurring mostly near clouds (Eq. 3).

$$
\begin{aligned}
& R_{\mathrm{rs}}(678)<0 \\
& R_{\mathrm{rc}}(748)<R_{\mathrm{rc}}(859) \\
& R_{\mathrm{rc}}(645)<R_{\mathrm{rc}}(531)
\end{aligned}
$$

\section{Results}

\subsection{Comparison with previous algorithms}

The detection results of the three Trichodesmium detection algorithms are illustrated in Fig. 5 on the MODIS tile A2007290.0355, used in McKinna et al. (2011). The McKinna modified algorithm shows the same detection patterns as the ones found in McKinna et al. (2011). It is a vast Trichodesmium area within which the filamentous structures cannot be distinguished. The new algorithm and the threshold FAI detect thin filamentous structures more similar to Trichodesmium mat structures observed in airborne photographs. When negative, the absolute value of $R_{\mathrm{rs}}(678)$ can also be used as an index of mat concentrations as values increase when getting to the core of patches.

Compared with both former algorithms, the new algorithm performs much better near clouds. Figure 6 is a zoom of the area delineated by the red rectangle in Fig. 5. This area presents a cloud patch in which McKinna modified and FAI algorithms both detect Trichodesmium pixels. These pixels were identified as false positives as their spatial distribution is sparse and only in the vicinity of clouds. This conclusion is also supported by the true color composition (Fig. 2) for which the only Trichodesmium mats appear located at the bottom of the image. In that area the new algorithm does not make any false positive detection while keeping the Trichodesmium mats at the bottom of the image. The robustness of the new detection algorithm to exclude cloudcontaminated pixels while keeping accurate Trichodesmium mat detection is an important improvement for regions with high cloudiness, such as the WTSP.

\subsection{Algorithm performance against in situ mat observations}

The exact coincidence in time and space between in situ Trichodesmium mat observations and satellite mat detection is quite difficult to reach in general. One of the main reasons is the cloud cover, which eliminates a large quantity of the possible comparisons $(90 \%)$. A second reason is the elapsed time between in situ observations and the corresponding satellite pass during which the floating algae could have drifted at sea surface and/or migrated vertically depending on sea conditions (temperature, wind, etc.). For example, the abundance of Trichodesmium at the sea surface may vary with the time of day, as a daily cycle of rising and sinking colonies in the water column is often observed as a result of cell ballasting (Villareal and Carpenter, 2003). Moreover, as Trichodesmium is a buoyant constituent, it can be advected by surface currents.

To circumvent that problem and perform a more statistically robust comparison of the detection results of our algorithm with in situ data, we used the following strategy. An analysis of the spatiotemporal distance between the in situ 

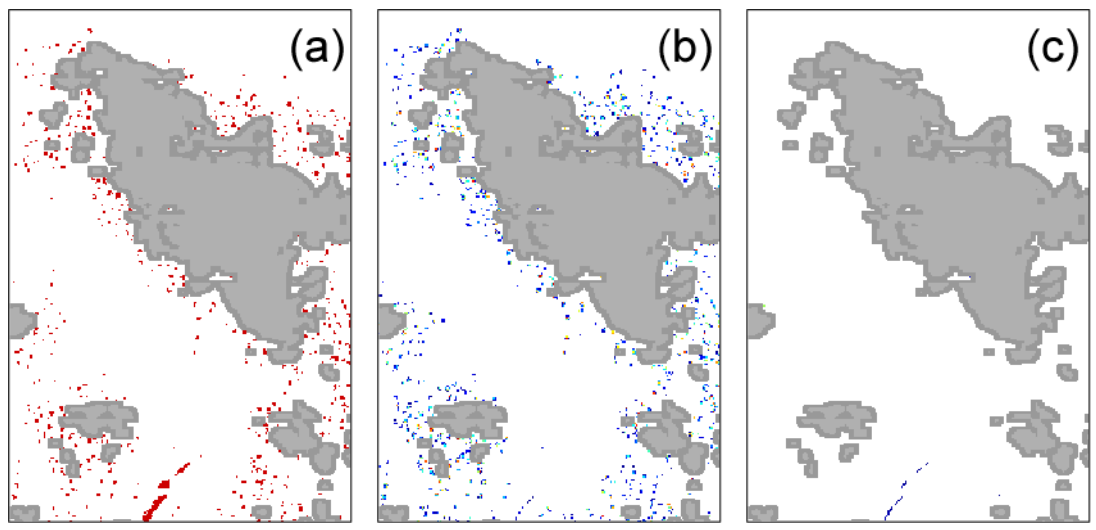

Figure 6. MODIS tile "A2007290.0355" zoom of the red square area (24 S, Fig. 5). Pixels resulting from a false positive detection of (a) the McKinna modified algorithm, (b) FAI, and (c) the new algorithm for the area in red in Fig. 5. Cloud pixels are in grey.

observations and the nearest detected mats was conducted. As explained previously, for each day in a range of \pm 4 days around the date of observation, the spatial distance between the position of the observation and the nearest detected mat was computed. Overall, $80 \%$ of the observed mats have a corresponding mat detection within a less than $5 \mathrm{~km}$ range independent of the detection algorithm used. These results demonstrate the statistical capability of the new algorithm to retrieve a mat near a point of observation.

\subsection{Algorithm application for the OUTPACE cruise}

The new algorithm was applied to MODIS data acquired during the OUTPACE cruise time. A total of 140 tiles at $250 \mathrm{~m}$ resolution covered the time period 15 February-7 April 2015 and the spatial area of the cruise. Due to high cloud cover during the cruise, only a few tiles were exploitable. Trichodesmium mats were detected from 12 MODIS Aqua and three MODIS Terra tiles. Figure $7 \mathrm{~b}$ shows the detected mats over these tiles (in blue). Note that the OUTPACE cruise actually crossed a number of Trichodesmium satellite detections. In order to further illustrate the results, a crude qualitative presence-absence scheme was applied to better visualize which OUTPACE stations were coincident with the algorithm positive detection. We selected areas within $50 \mathrm{~km}$ of each OUTPACE station and labeled the station presence when there was at least 1 pixel detected as positive in the satellite algorithm. In Fig. 7b, the red points indicate presence and blue points absence.

Trichodesmium mats were mostly observed visually northeast of New Caledonia 1 week before the cruise and during the first days of the cruise (onboard observation) by video and photographs. No other mats were observed during the rest of the cruise, but there was not any dedicated observer who would actually permit such visual observation, unlike during the (REMMOA) campaigns. Nevertheless, Underwater Vision Profiler 5 (UVP5) counts of colonies and phycoerythrin and trichome concentrations along the transect show that Trichodesmium contribution was maximum in the Melanesian Archipelago, i.e., the western part of the transect, where slicks are numerous, and then fairly well related to Trichodesmium concentrations in the upper layer (Dupouy et al., 2018). The other high spot of mats detected in the satellite imagery is at LDB (station name in OUTPACE), where no slick was observed but where Trichodesmium was in high concentration, although mixed with a high abundance of picoplanktonic cyanobacteria (Dupouy et al., 2018).

Bonnet et al. (2018) reported a significant $(p<0.05)$ correlation between $\mathrm{N}_{2}$ fixation rates and Trichodesmium abundances during OUTPACE. Based on bulk and cell-specific $\mathrm{N}_{2}$-based isotopic measurements, Trichodesmium accounted for 50 to $>80 \%$ of $\mathrm{N}_{2}$ fixation rates in this region at the time of the cruise. Such a high correlation between Trichodesmium biomass (here phycoerythrin) was also measured in New Caledonia waters (Tenório et al., 2018). Hence, the in situ $\mathrm{N}_{2}$ fixation rate measured during the cruise (Fig. 7a) was used as a robust proxy of the Trichodesmium concentration to further evaluate accuracy of satellite detections. A qualitative comparison between Fig. $7 \mathrm{a}$ and $\mathrm{b}$ indicates that when significant fixation rates were observed, Trichodesmium presence was detected by the satellite algorithm and when $\mathrm{N}_{2}$ fixation rates were low, Trichodesmium absence was stated. Although qualitative, this successful validation gives confidence in using our algorithm for Trichodesmium detection.

\section{Discussion}

\subsection{Algorithm limitations}

The proposed algorithm was designed to detect strong concentrations of floating Trichodesmium mats and limit wrong detections. However, floating Trichodesmium mats occur when the sea surface is not very agitated since they tend to sink and disperse in rough conditions. In such a case our al- 

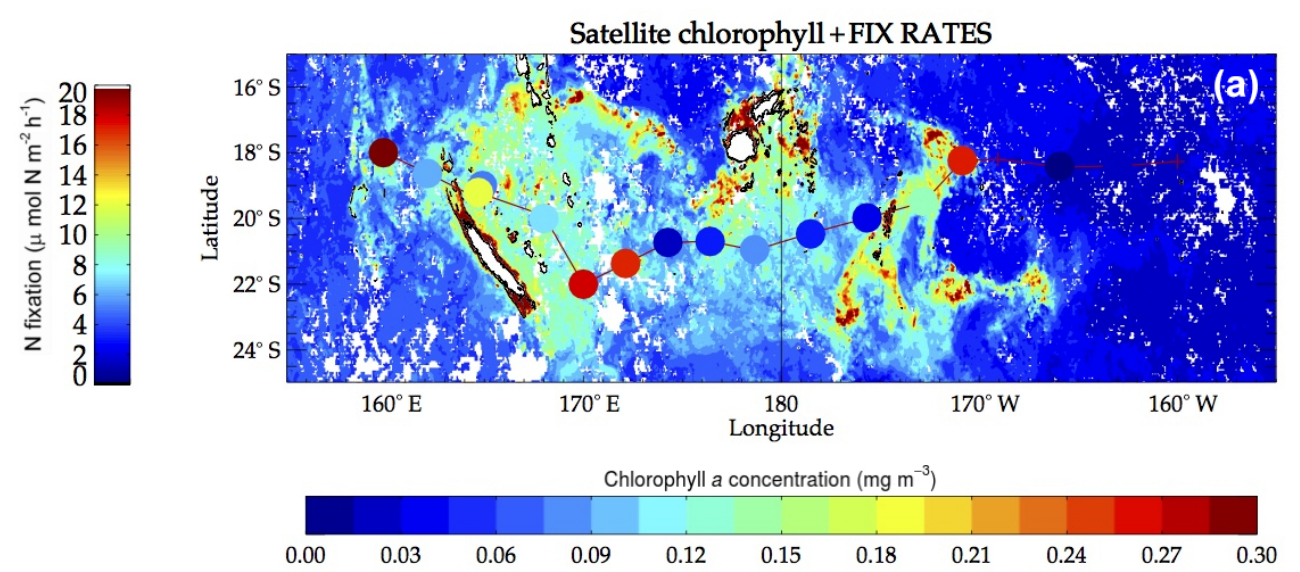

Trichodesmium detection by the algorithm

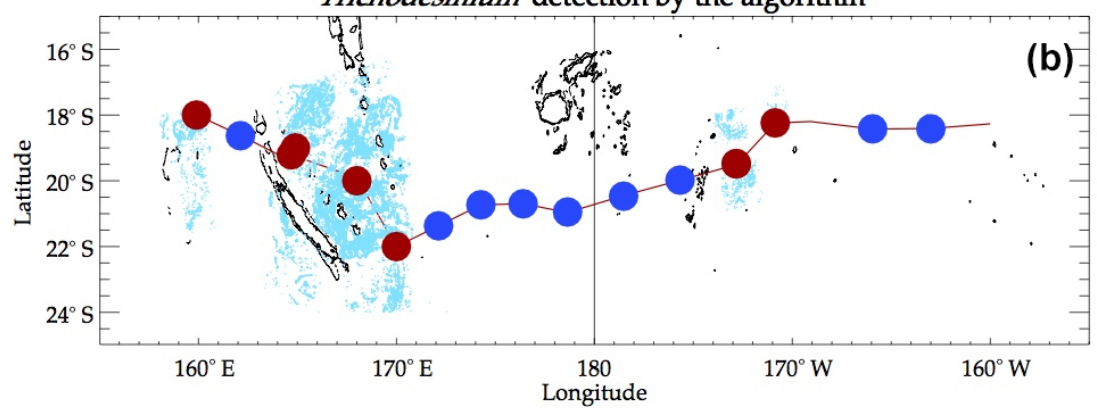

Figure 7. (a) Background is the monthly composite of satellite chlorophyll for March 2015, with the corresponding chlorophyll $a$ concentrations given by the color bar underneath the map. Superimposed colored dots are in situ fixation rates measured on the OUTPACE track with values given by the left color bar. (b) In the background, cyan pixels are pixels detected as Trichodesmium by our algorithm. The colored dots superimposed show the absence (blue) or presence (red) of detected pixels within a radius of $50 \mathrm{~km}$ around OUTPACE stations.

gorithm does not allow the detection of Trichodesmium even at strong concentrations because of the low penetration depth of NIR irradiance (below $1 \mathrm{~m}$ ). This situation occurred during the OUTPACE cruise, for which measurements reveal high Trichodesmium abundances near the Fiji island (Stenegren et al., 2018), while our algorithm was unable to detect Trichodesmium mats (Fig. 7, stations adjacent $180^{\circ} \mathrm{E}$ ).

Another limitation concerns the validity of the new algorithm for future MODIS collections and other regions. The first criterion is taking advantage of the aerosol overcorrection as an index of floating algae. The aerosol correction algorithm will certainly be adapted in the future. Thus, the first criterion would have to be replaced by another floating algae index; the FAI could be a good solution. However, it will always be possible to use the current (imperfect) aerosol correction. Moreover, the zero threshold on $R_{\mathrm{rs}}(678)$, under which the pixel is labeled as a Trichodesmium mat, would have to be tested and tuned in other situations, e.g., in the presence of aerosols and other floating material. This study was carried out in the WTSP area, where the observed spectra seem slightly different from the ones reported in McKinna et al. (2011) and Hu et al. (2010). More specifically, the spectral oscillations of reflectance observed by Hu et al. (2010) in the range $[412,678] \mathrm{nm}$ were not noticed in the present study.
Therefore, the robustness of this algorithm in the presence of other floating algae (e.g., Sargassum), as well as in other regions of the world, would have to be tested to make it more general.

This study was limited to the processing of MODIS images, mainly because of the availability of images corresponding to field measurements (2014 and before). However, it would be worth extending the detection algorithm to other sensors such as MERIS, e.g., for comparison with the Gower et al. (2014) algorithm, and the recently launched Ocean and Land Colour Instrument (OLCI). This would require further investigations to adapt the algorithm to the specific bands of these sensors and evaluate the results. However, since these sensors cover the same spectral range, one can expect a quite similar behavior.

Aware of these limitations, one may consider using $R_{\mathrm{rc}}$ only since $R_{\mathrm{rs}}$ is sensitive to the accuracy of the atmospheric correction. To emulate an index of mat concentrations, Eq. (4) is proposed in place of Eq. (1). The magnitude of the trough at $678 \mathrm{~nm}$ is an indication of the mat concentrations, which can be retrieved using the difference between the observed $R_{\mathrm{rc}}(678)$ and the result of the linear $R_{\mathrm{rc}}$ interpolation between 645 and $748 \mathrm{~nm}$. In the following, To confirm the trough at $678 \mathrm{~nm}$, check the spectral form typical to Tri- 
chodesmium (Fig. 4) and assess the red edge of the signal, Eqs. (5)-(7), similar to the form criteria of McKinna et al. (2011), could be used.

$$
\begin{aligned}
& {\left[R_{\mathrm{rc}}(645)+\left(R_{\mathrm{rc}}(748)-R_{\mathrm{rc}}(645)\right)\right.} \\
& \left.\quad \times \frac{678-645}{748-645}\right]-R_{\mathrm{rc}}(678)>0 \\
& R_{\mathrm{rc}}(678)<R_{\mathrm{rc}}(859) \\
& R_{\mathrm{rc}}(678)<R_{\mathrm{rc}}(748) \\
& R_{\mathrm{rc}}(678)<R_{\mathrm{rc}}(667)
\end{aligned}
$$

This alternative algorithm has the advantage of being easily adaptable to other sensors with similar spectral bands (e.g., MODIS). Moreover, the procedure is free of atmospheric overcorrection while still exploiting the red-edge effect. However, in its application, a large number of pixels detected as Trichodesmium by the former algorithm (i.e., described in Sect. 3.5) are discarded. The different criteria cannot be relaxed without a false positive detection increase. Therefore, this alternative algorithm is more restrictive, and its suitability and performance require further examination.

\subsection{Spatial resolution impact}

As indicated previously, only a few spectral bands (land channels) have a high resolution ( 250 or $500 \mathrm{~m}$ ), while the rest have a nominal resolution at $1 \mathrm{~km}$. To investigate the influence of resolution on the spectral signature of Trichodesmium mats, the spectral analysis was also conducted at a $1 \mathrm{~km}$ resolution. Dense groups of extended mats are still well detected at $1 \mathrm{~km}$ resolution. However, thinner mats with a weaker signal visible at $250 \mathrm{~m}$ resolution are lost at $1 \mathrm{~km}$ resolution. Figure 8 illustrates this behavior for MODIS data.

The spatial structure of Trichodesmium aggregates is complex. When mats are present, Trichodesmium have a tendency to form a filamentous pattern much narrower than $250 \mathrm{~m}$ (50 m at most, according to visual detections), and thus the satellite sensor at $250 \mathrm{~m}$ resolution can only detect the largest ones (Figs. 8 and 9). Hence, there is a scale mismatch between the exact form of the thin filaments and the actual detection by the current satellite data, which must in a way average the thin and strongest filaments into signals detectable at $250 \mathrm{~m}$. Understanding the shape of the filaments and their physical characteristics (e.g., width) will require much higher-resolution satellite data (at least $50 \mathrm{~m}$ ), which are available at present but without repetitive coverage. Figure 9 additionally illustrates that the Trichodesmium filaments are but a tiny part of the chlorophyll tongues and are inserted into the much wider chlorophyll patterns. There can be, within a chlorophyll tongue such as that in Fig. 9, several thin elongated filaments.

One would also intuitively believe that the filaments illustrate the presence of dynamical fronts where convergent dynamics can maintain and participate in the mat aggregations. A natural dynamical criteria allowing one
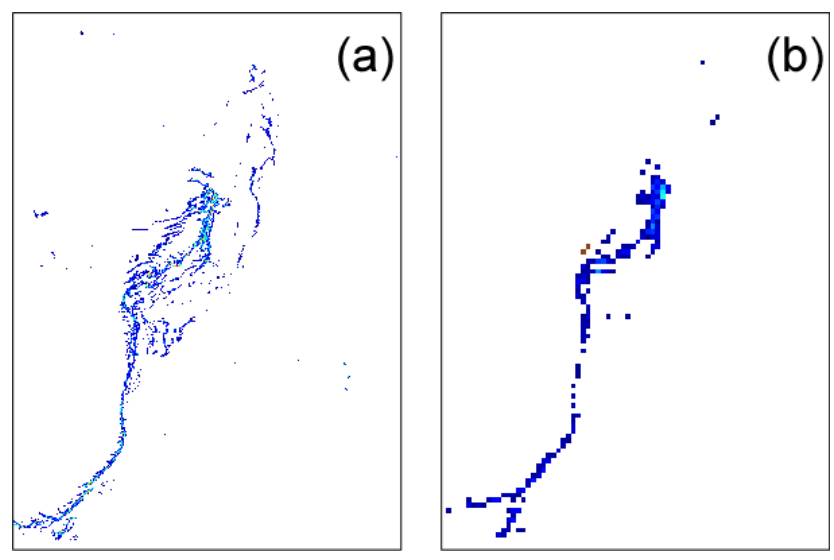

Figure 8. FAI application to the MODIS tile "A2007290.0355": zoom of the area in the green square $\left(22.5^{\circ} \mathrm{S}\right.$, Fig. 5). (a) Results at $250 \mathrm{~m}$ resolution; (b) the same scene at $1 \mathrm{~km}$ resolution. Only a few pixels remain, corresponding to the densest part of the surface mat, showing the loss of detected mats.

to characterize the presence of the filaments could be found in the finite-size Lyapunov exponent (FSLE) methods (Rousselet et al., 2018). A relationship between FSLE only and in situ chlorophyll edge "fronts" was found during OUTPACE with a $25 \%$ correlation score. The same kind of relationship was expected for floating algae filaments. However, the relationship between FSLE and the organization of the filaments could not be proven within this study. We believe that it is also a question of scale here. The present calculation of FSLE is uses $12.5 \mathrm{~km}$ satellite data at best (Rousselet et al., 2018); thus it is difficult to think that such a resolution could catch dynamics Trichodesmium filaments wide of a few hundred meters. A dedicated in situ experiment would have to be specifically undertaken to resolve the question of filament organization.

\section{Conclusions and perspectives}

At present, previously published algorithms detecting Trichodesmium using the current MODIS data archive (Hu et al., 2010; McKinna et al., 2011) cannot be directly used in the South Pacific as they either miss the mats due to algorithm failures (Sect. 3.4) and/or do not eliminate numerous false positives in the presence of clouds. In our study, we have devised a new algorithm building on the previous ones, which allows a cleaner and more robust detection of those mats. Validation was accomplished using a new, updated database of mats in the South Pacific. This algorithm can however only detect the densest slick but achieves the goal of limiting the detection of false positive due to clouds. During the OUTPACE cruise, satellite detections confirmed the presence of Trichodesmium slicks at a much wider spatial range than what was possible to observe from the ship. This illustrates the important contribution and complementary na- 


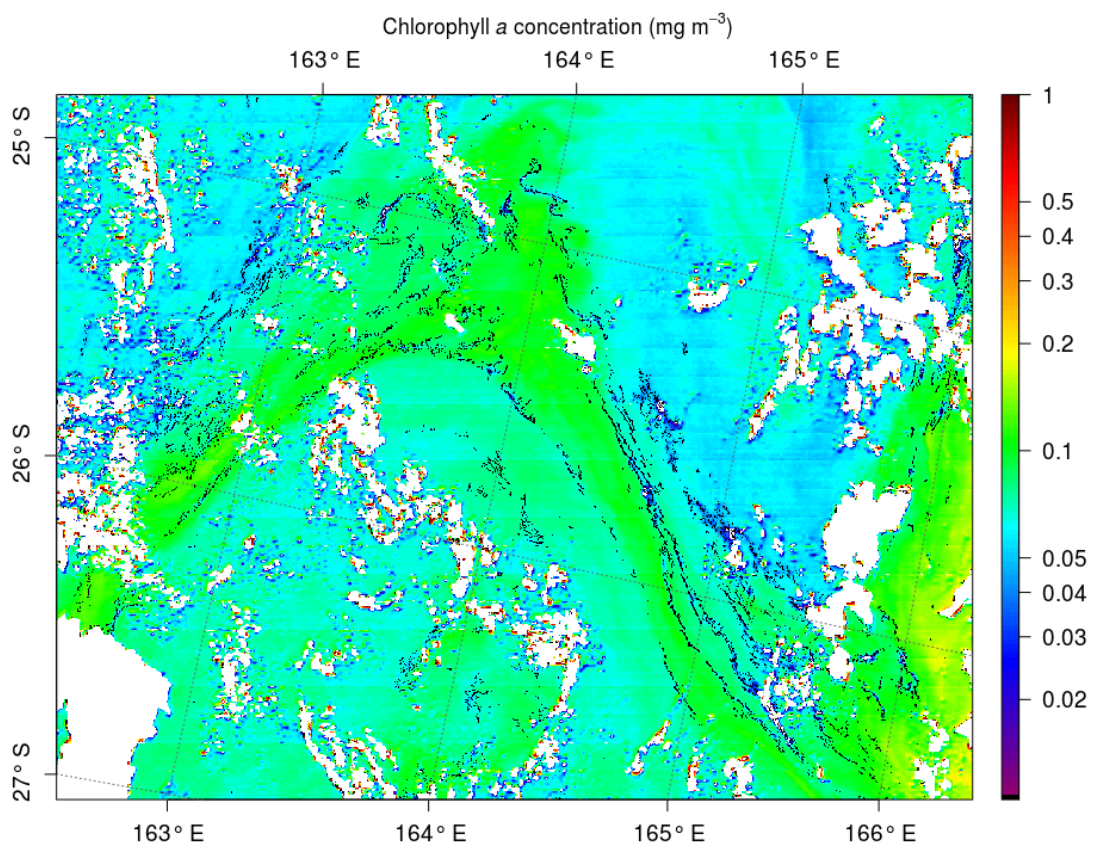

Figure 9. MODIS Aqua image at $250 \mathrm{~m}$ taken on 6 March 2015 to the south of the OUTPACE cruise, illustrating the structure of the chlorophyll (colors) together with the filaments of Trichodesmium detected by our algorithm (in black). Cloud pixels are in white.

ture of satellite observations to in situ measurements. Yet, the new detection algorithm was developed and evaluated for the WTSP region. Hence, future prospects will be to extend the evaluation to other regions, especially in the presence of other floating algae such as Sargassum.

During the same campaign Dupouy et al. (2018) found that ocean color measured with a Satlantic UV-VIS radiometer at greenish blue and yellowish green wavelengths was not totally linked to $\mathrm{Chl} a$ and that an extra factor independent of Chl $a$, maybe related to colony backscattering or fluorescence, governs part of the variability. This extra factor is not observed during BIOSOPE (Biogeochemistry and Optics South Pacific Experiment), a cruise in the tropical Southern Pacific gyre (Claustre et al., 2008), where the radiance is correlated to Chl $a$ only. Further investigations have to be conducted to confirm that such a signal is produced by Trichodesmium and can be detected from space.

MODIS Terra and MODIS Aqua satellite sensors have been acquiring data since 2000 and 2002, respectively. However, the data quality of these sensors is becoming more and more uncertain with time, as their lifetime was not expected to last more than 6 years. The new algorithm could be adapted to other satellite instruments with similar spectral bands, for example the Visible Infrared Imaging Radiometer Suite (VIIRS) onboard NPP and JPSS-1/NOAA-20 (1 km resolution) and OLCI onboard Sentinel-3 (300 m spatial sampling), but the spatial resolution remains a problem as we observed that $250 \mathrm{~m}$ was already too coarse a resolution to understand the thinner mat dynamics. A study with better spectral and spatial resolution may lead to better performances and to a new and better algorithm. This may be possible, at least regarding spatial resolution, with the Multispectral Instrument (MSI) onboard the Sentinel-2 series (10 to $60 \mathrm{~m}$ resolution).

It has previously been documented that near dense Trichodesmium mats some satellite products like the satellite chlorophyll concentration are inaccurate. In order to better constrain the contribution of Trichodesmium to nitrogen and carbon biogeochemical cycles, this algorithm must be corrected. Using $R_{\mathrm{rc}}$ instead of $R_{\mathrm{rs}}$ is possible (Sect. 5.1), but some adjustments and comparisons with in situ measurements must first be carried out. Globally such an algorithm would allow one to estimate the Trichodesmium amount aggregated in sea surface mats. The next step is to understand the quantitative aspect linking the Trichodesmium abundances to $\mathrm{N}_{2}$ fixation rates, including their vertical distribution even when Trichodesmium filaments/colonies are spread out in the water column. Another important field of interest is to be able to understand phytoplankton functional types using satellites including Trichodesmium (de Boissieu et al., 2014). At present, we do not know any such study that included Trichodesmium but we have hopes that with our new in situ database and our understanding of the mat shapes detected in the present study, and the development of performing statistical methods such as machine learning, advances can be made in that regard, a prospect for future work.

Finally, Dutheil et al. (2018) explore the regional and seasonal budget of the $\mathrm{N}_{2}$ fixation due to Trichodesmium in a numerical model based on physical and biogeochemical properties that does not take into consideration the spatial charac- 
teristic of Trichodesmium colonies to aggregate in mats. One interesting aspect will be to find a way to integrate our results into such a model to better estimate the regional effects of that species.

Data availability. Satellite data are publicly accessible at https: //oceandata.sci.gsfc.nasa.gov/ (NASA Goddard Space Flight Center, 2014). Data from the OUTPACE cruise under the PI responsibilities (described at http://www.obs-vlfr.fr/proof/php/outpace/ outpace.php, INSU/CNRS LEFE CYBER, 2017). Access to the data is available with PI permission. REMMOA database available only with private access; a request should be acquired from Sophie Laran or Vincent Ridoux (slaran@univ-lr.fr, vincent.ridoux@univ-lr.fr). French Navy and other Trichodesmium observations accessible at https://doi.org/10.5194/bg-8-3631-2011 (Dupouy et al., 2011). 


\section{Appendix A: McKinna et al. (2011) algorithm}

The McKinna et al. (2011) algorithm is based on the analysis of the above-water reflectance spectrum of a moderate Trichodesmium mat, similar to the one measured on colonies in a small dish with an Ocean Optics spectroradiometer (Dupouy et al., 2008). It uses typical spectral characteristics of the normalized water-leaving radiance $(\mathrm{nLw})$ after atmospheric correction to define four Trichodesmium detection criteria. The first three criteria relate to the shape of the spectrum and the last criterion discards any pixel with negative $\mathrm{nLw}$. When these four criteria are respected the pixel is identified as revealing the presence of Trichodesmium.

$\mathrm{nLw}(859)>c 1 . \mathrm{nLw}(678)$

$\mathrm{nLw}(645)>\mathrm{nLw}(678)$

$\mathrm{nLw}(555)>\mathrm{nLw}(678)$

$\mathrm{nLw}(555), \mathrm{nLw}(645), \mathrm{nLw}(678), \mathrm{nLw}(859)<0$

\section{Appendix B: Hu et al. (2010) algorithm}

The detection algorithm, originally developed by (Hu, 2009) for floating algae, can be applied to Trichodesmium mats, as demonstrated by Hu et al. (2010) on MODIS Aqua images of the west coast of Florida and the Gulf of Mexico, even though the Trichodesmium mats occurred in Case 2 waters. This algorithm can be decomposed into two steps: (1) detection of floating algae (FAI, floating algae index), and (2) testof-form criteria of the radiance spectrum.

The FAI aims to detect the strong reflectance in the infrared (red edge) of the algal agglomerate. To avoid the atmospheric overcorrection linked to the red-edge effect of the floating algae organized in a heap (Hu, 2009), the calculation of this index is applied to reflectance corrected only for the effects of Rayleigh scattering $\left(R_{\mathrm{rc}}\right)$. This correction accounts for the major part of the color of the atmosphere if aerosols are not too abundant (i.e., small optical thickness). The FAI is then defined as the difference between $R_{\mathrm{rc}}$ in the infrared $(859 \mathrm{~nm}$ for MODIS $)$ and a reference reflectance $\left(R_{\mathrm{rc}, 0}\right)$ calculated using linear interpolation between the red and shortwave infrared, i.e., 667 and $1240 \mathrm{~nm}$ for MODIS:
$R_{\mathrm{rc}, \mathrm{NIR}}+\left(R_{\mathrm{rc}, \mathrm{SWIR}}-R_{\mathrm{rc}, \mathrm{RED}}\right) \times \frac{\lambda_{\mathrm{NIR}}-\lambda_{\mathrm{RED}}}{\lambda_{\mathrm{SWIR}}-\lambda_{\mathrm{RED}}}$,

$\lambda_{\mathrm{RED}}=645 \mathrm{~nm}, \lambda_{\mathrm{NIR}}=859 \mathrm{~nm}, \lambda_{\mathrm{SWIR}}=1240 \mathrm{~nm}$,

where $\mathrm{RED}=645 \mathrm{~nm}, \mathrm{NIR}=859 \mathrm{~nm}$, and $\mathrm{SWIR}=$ $1240 \mathrm{~nm}$. According to $\mathrm{Hu}$ et al. (2010), the difference between $R_{\mathrm{rc}}$ and $R_{\mathrm{rc}, 0}$ (the second term of Eq. B1) allows one to deal with the majority of the atmospheric effect, which has a quasi-linear spectral shape between 667 and $1240 \mathrm{~nm}$. The second step of the algorithm consists in identifying the mats emphasized by the FAI thanks to the shape of the spectrum in the visible domain. So as to correct the bias inferred in the visible part of the spectrum by the possible presence of mats, Hu et al. (2010) suggest applying the correction of an area situated immediately next to this pixel and without bloom to the pixels presenting a strong FAI value. This approach being very computer expensive, it is substituted by a simple difference between the $R_{\mathrm{rc}}$ spectrum of the pixels considered (i.e., eventually with Trichodesmium) and that of a nearby zone without mat. The spectrum of this $R_{\mathrm{rc}}$ difference presents a pattern (spectral signature) that seems to be specific to Trichodesmium presence, i.e., a succession of high-type low-top-low-top for the wavelengths 469-488-531-551-555 nm. 
Author contributions. GR conceived the study. FDB, CEM, JL, and RF provided technical support. VR and SL provided the REMMOA data. MR, SB, and CD participated in the collection and analysis of samples. GR and FDB wrote the manuscript with contributions from CEM, JL, RF, SB, and CD.

Competing interests. The authors declare that they have no conflict of interest.

Special issue statement. This article is part of the special issue "Interactions between planktonic organisms and biogeochemical cycles across trophic and $\mathrm{N}_{2}$ fixation gradients in the western tropical South Pacific Ocean: a multidisciplinary approach (OUTPACE experiment)". It is not associated with a conference.

Acknowledgements. Robert Frouin is supported by the National Aeronautics and Space Administration under various grants. We thank NASA for the MODIS products.

Edited by: Thierry Moutin

Reviewed by: two anonymous referees

\section{References}

Bailey, S. W. and Werdell, P. J.: A multi-sensor approach for the on-orbit validation of ocean color satellite data products, Remote Sens. Environ., 102, 12-23, https://doi.org/10.1016/j.rse.2006.01.015, 2006.

Berthelot, H., Benavides, M., Moisander P, H., Grosso, O., and Bonnet, S.: High-nitrogen fixation rates in the particulate and dissolved pools in the Western Tropical Pacific (Solomon and Bismarck Seas), Geophys. Res. Lett., 44, 8414-8423, https://doi.org/10.1002/2017GL073856, 2017.

Blondeau-Patissier, D., Gower, J. F. R., Dekker, A. G., Phinn, S. R., and Brando, V. E.: A review of ocean color remote sensing methods and statistical techniques for the detection, mapping and analysis of phytoplankton blooms in coastal and open oceans, Elsevier Ltd, https://doi.org/10.1016/j.pocean.2013.12.008, 2014.

Bonnet, S., Biegala, I. C., Dutrieux, P., Slemons, L. O., and Capone, D. G.: Nitrogen fixation in the western equatorial Pacific: Rates, diazotrophic cyanobacterial size class distribution, and biogeochemical significance, Global Biogeochem. Cy., 23, 1-13, https://doi.org/10.1029/2008GB003439, 2009.

Bonnet, S., Rodier, M., Turk-Kubo, K., Germineaud, C., Menkes, C., Ganachaud, A., Cravatte, S., Raimbault, P., Campbell, E., Quéroué, F., Sarthou, G., Desnues, A., Maes, C., and Eldin, G.: Contrasted geographical distribution of N2 fixation rates and nifH phylotypes in the Coral and Solomon Seas (southwestern Pacific) during austral winter conditions, Global Biogeochem. Cy., 29, 1874-1892, https://doi.org/10.1002/2015GB005117, 2015

Bonnet, S., Caffin, M., Berthelot, H., and Moutin, T.: Hot spot of N2 fixation in the western tropical South Pacific pleads for a spatial decoupling between $\mathrm{N} 2$ fixation and denitrification, P. Natl. Acad. Sci. USA, 114, E2800-E2801, https://doi.org/10.1073/pnas.1619514114, 2017.

Bonnet, S., Caffin, M., Berthelot, H., Grosso, O., Benavides, M., Helias-Nunige, S., Guieu, C., Stenegren, M., and Foster, R. A.: In-depth characterization of diazotroph activity across the western tropical South Pacific hotspot of N2 fixation (OUTPACE cruise), Biogeosciences, 15, 4215-4232, https://doi.org/10.5194/bg-15-4215-2018, 2018.

Caffin, M., Moutin, T., Foster, R. A., Bouruet-Aubertot, P., Doglioli, A. M., Berthelot, H., Guieu, C., Grosso, O., Helias-Nunige, S., Leblond, N., Gimenez, A., Petrenko, A. A., de Verneil, A., and Bonnet, S.: N2 fixation as a dominant new $\mathrm{N}$ source in the western tropical South Pacific Ocean (OUTPACE cruise), Biogeosciences, 15, 2565-2585, https://doi.org/10.5194/bg-152565-2018, 2018.

Capone, D. G.: Trichodesmium, a Globally Significant Marine Cyanobacterium, American Association for the Advancement of Science, 1997

Casey, K. A., Polashenski, C. M., Chen, J., and Tedesco, M.: Impact of MODIS sensor calibration updates on Greenland Ice Sheet surface reflectance and albedo trends, The Cryosphere, 11, 17811795, https://doi.org/10.5194/tc-11-1781-2017, 2017.

Claustre, H., Sciandra, A., and Vaulot, D.: Introduction to the special section bio-optical and biogeochemical conditions in the South East Pacific in late 2004: the BIOSOPE program, Biogeosciences, 5, 679-691, https://doi.org/10.5194/bg-5-6792008, 2008.

Cravatte, S., Kestenare, E., Eldin, G., Ganachaud, A., Lefèvre, J., Marin, F., Menkes, C., and Aucan, J.: Regional circulation around New Caledonia from two decades of observations, J. Marine Syst., 148, 249-271, https://doi.org/10.1016/j.jmarsys.2015.03.004, 2015.

de Boissieu, F., Menkes, C., Dupouy, C., Rodier, M., Bonnet, S., Mangeas, M., and Frouin, R. J.: Phytoplankton global mapping from space with a support vector machine algorithm, in: Ocean Remote Sensing and Monitoring from Space, edited by: Frouin, R. J., Pan, D., and Murakami, H., https://doi.org/10.1117/12.2083730, 2014.

Dupouy, C., Jacques, N., Subramaniam, A., R. Mulholland, M., Montoya, J., Campbell, L., and Capone, D. G.: Satellite captures Trichodesmium blooms in the Soutwestern Tropical Pacific, EOS T. Am. Geophys. Un., 81, 13-20, https://doi.org/10.1029/00EO00008, 2000.

Dupouy, C., Neveux, J., Dirberg, G., Röttgers, R., Barboza Tenório, M. M., and Ouillon, S.: Bio-optical properties of the marine cyanobacteria Trichodesmium spp., J. Appl. Remote Sens., 2, 023503, https://doi.org/10.1117/1.2839036, 2008.

Dupouy, C., Benielli-Gary, D., Neveux, J., Dandonneau, Y., and Westberry, T. K.: An algorithm for detecting Trichodesmium surface blooms in the South Western Tropical Pacific, Biogeosciences, 8, 3631-3647, https://doi.org/10.5194/bg-8-36312011, 2011.

Dupouy, C., Frouin, R., Tedetti, M., Maillard, M., Rodier, M., Lombard, F., Guidi, L., Picheral, M., Duhamel, S., Charrière, B., and Sempéré, R.: Diazotrophic Trichodesmium influence on ocean color and pigment composition in the South West tropical Pacific, Biogeosciences Discuss., https://doi.org/10.5194/bg-2017570, in review, 2018. 
Dutheil, C., Aumont, O., Gorguès, T., Lorrain, A., Bonnet, S., Rodier, M., Dupouy, C., Shiozaki, T., and Menkes, C.: Modelling $\mathrm{N}_{2}$ fixation related to Trichodesmium sp.: driving processes and impacts on primary production in the tropical Pacific Ocean, Biogeosciences, 15, 4333-4352, https://doi.org/10.5194/bg-154333-2018, 2018.

Garcia, N., Raimbault, P., and Sandroni, V.: Seasonal nitrogen fixation and primary production in the Southwest Pacific: Nanoplankton diazotrophy and transfer of nitrogen to picoplankton organisms, Mar. Ecol.-Prog. Ser., 343, 25-33, https://doi.org/10.3354/meps06882, 2007.

Gordon, H. R. and Wang, M.: Retrieval of water-leaving radiance and aerosol optical thickness over the oceans with SeaWiFS: a preliminary algorithm, Appl. Opt., 33, 443-452, https://doi.org/10.1364/AO.33.000443, 1994.

Gower, J., King, S., and Goncalves, P.: Global monitoring of plankton blooms using MERIS MCI, Int. J. Remote Sens., 29, 62096216, https://doi.org/10.1080/01431160802178110, 2008.

Gower, J., King, S., and Young, E.: Global remote sensing of Trichodesmium, Int. J. Remote Sens., 35, 5459-5466, https://doi.org/10.1080/01431161.2014.926422, 2014.

Hegde, S., Anil, A., Patil, J., Mitbavkar, S., Krishnamurthy, V., and V. Gopalakrishna, V.: Influence of environmental settings on the prevalence of Trichodesmium spp. in the Bay of Bengal, Mar. Ecol.-Prog. Ser., 356, 93-101, 2008.

$\mathrm{Hu}, \mathrm{C} .:$ A novel ocean color index to detect floating algae in the global oceans, Remote Sens. Environ., 113, 2118-2129, https://doi.org/10.1016/j.rse.2009.05.012, 2009.

Hu, C., Cannizzaro, J., Carder, K. L., Muller-Karger, F. E., and Hardy, R.: Remote detection of Trichodesmium blooms in optically complex coastal waters: Examples with MODIS fullspectral data, Remote Sens. Environ., 114, 2048-2058, 2010.

Hu, C., Lee, Z., and Franz, B.: Chlorophyll a algorithms for oligotrophic oceans: A novel approach based on three-band reflectance difference, J. Geophys. Res.-Oceans, 117, 1-25, https://doi.org/10.1029/2011JC007395, 2012.

INSU/CNRS LEFE CYBER: OUTPACE - Oligotrophy to UlTraoligotrophy PACific Experiment, available at: http://www. obs-vlfr.fr/proof/php/outpace/outpace.php (last access: $13 \mathrm{Au}-$ gust 2018), 2017.

Knapp, A. N., McCabe, K. M., Grosso, O., Leblond, N., Moutin, T., and Bonnet, S.: Distribution and rates of nitrogen fixation in the western tropical South Pacific Ocean constrained by nitrogen isotope budgets, Biogeosciences, 15, 2619-2628, https://doi.org/10.5194/bg-15-2619-2018, 2018.

Laran, S., Hamani, V., Authier, M., Dorémus, G., Van Canneyt, O., Ridoux, V., and Watremez, P.: Distribution et abondance de la mégafaune marine dans le sud-ouest du Pacifique. Campagne REMMOA - Nouvelle-Calédonie et Wallis et Futuna, Rapport final pour l'Agence des aires marines protégées, 105 pp., 2016.

Le Borgne, R., Allain, V., Griffithos, S. P., Matear, R. J., McKinnon, D. A., Richardson, A. J., and Young, J. W.: Vulnerability of open ocean food webs in the tropical Pacific to climate change, in: Vulnerability of tropical Pacific fisheries and aquaculture to climate change, 189-249, SPC, available at: http: //www.documentation.ird.fr/hor/fdi:010058145 (last access: 13 August 2018), 2011.

Luo, Y.-W., Doney, S. C., Anderson, L. A., Benavides, M., BermanFrank, I., Bode, A., Bonnet, S., Boström, K. H., Böttjer, D.,
Capone, D. G., Carpenter, E. J., Chen, Y. L., Church, M. J., Dore, J. E., Falcón, L. I., Fernández, A., Foster, R. A., Furuya, K., Gómez, F., Gundersen, K., Hynes, A. M., Karl, D. M., Kitajima, S., Langlois, R. J., LaRoche, J., Letelier, R. M., Marañón, E., McGillicuddy Jr., D. J., Moisander, P. H., Moore, C. M., Mouriño-Carballido, B., Mulholland, M. R., Needoba, J. A., Orcutt, K. M., Poulton, A. J., Rahav, E., Raimbault, P., Rees, A. P., Riemann, L., Shiozaki, T., Subramaniam, A., Tyrrell, T., Turk-Kubo, K. A., Varela, M., Villareal, T. A., Webb, E. A., White, A. E., Wu, J., and Zehr, J. P.: Database of diazotrophs in global ocean: abundance, biomass and nitrogen fixation rates, Earth Syst. Sci. Data, 4, 47-73, https://doi.org/10.5194/essd-447-2012, 2012.

McKinna, L., Furnas, M., and Ridd, P.: A simple, binary classification algorithm for the detection of Trichodesmium spp. within the Great Barrier Reef using MODIS imagery, Limnol. Oceanogr.Meth., 9, 50-66, https://doi.org/10.4319/lom.2011.9.50, 2011.

Mckinna, L. I. W.: Three decades of ocean-color remote-sensing Trichodesmium spp. in the World's oceans: A review, Prog. Oceanogr., 131, 177-199, https://doi.org/10.1016/j.pocean.2014.12.013, 2015.

Moutin, T., Doglioli, A. M., de Verneil, A., and Bonnet, S.: Preface: The Oligotrophy to the UlTra-oligotrophy PACific Experiment (OUTPACE cruise, 18 February to 3 April 2015), Biogeosciences, 14, 3207-3220, https://doi.org/10.5194/bg-143207-2017, 2017.

NASA Goddard Space Flight Center, Ocean Ecology Laboratory, Ocean Biology Processing Group: NASA OB.DAAC, available at: https://oceancolor.gsfc.nasa.gov/ (last access: 13 August 2018), 2014.

Picheral, M., Guidi, L., Stemmann, L., Karl, D. M., Iddaoud, G., and Gorsky, G.: The Underwater Vision Profiler 5: An advanced instrument for high spatial resolution studies of particle size spectra and zooplankton, Limnol. Oceanogr.-Meth., 8, 462-473, https://doi.org/10.4319/lom.2010.8.462, 2010.

Rousselet, L., de Verneil, A., Doglioli, A. M., Petrenko, A. A., Duhamel, S., Maes, C., and Blanke, B.: Large- to submesoscale surface circulation and its implications on biogeochemical/biological horizontal distributions during the OUTPACE cruise (southwest Pacific), Biogeosciences, 15, 24112431, https://doi.org/10.5194/bg-15-2411-2018, 2018.

Shiozaki, T., Kodama, T., and Furuya, K.: Large scale impact of the island mass effect through nitrogen fixation in the western South Pacific Ocean, Geophys. Res., 41, 2907-2913, https://doi.org/10.1002/2014GL059835, 2014.

Stenegren, M., Caputo, A., Berg, C., Bonnet, S., and Foster, R. A.: Distribution and drivers of symbiotic and free-living diazotrophic cyanobacteria in the western tropical South Pacific, Biogeosciences, 15, 1559-1578, https://doi.org/10.5194/bg-151559-2018, 2018.

Subramaniam, A., Carpenter, E. J., and Falkowski, P. G.: Bio-optical properties of the marine diazotrophic cyanobacteria Trichodesmium spp. I. Absorption and photosynthetic action spectra, Limnol. Oceanogr., https://doi.org/10.4319/lo.1999.44.3.0618, 1999a.

Subramaniam, A., Carpenter, E. J., and Falkowski, P. G.: Biooptical properties of the marine diazotrophic cyanobacteria Trichodesmium spp. II. A reflectance model for remote-sensing, 
Limnol. Oceanogr., https://doi.org/10.4319/lo.1999.44.3.0618, 1999b.

Subramaniam, A., Brown, C. W., Hood, R. R., Carpenter, E. J., and Capone, D. G.: Detecting Trichodesmium blooms in SeaWiFS imagery, Deep-Sea Res. Pt. II, 49, 107-121, 2002.

Tenório, M. B., Dupouy, C., Rodier, M., and Neveux, J.: Trichodesmium and other planktonic cyanobacteria in New Caledonian waters (SW tropical Pacific) during an El Niño episode, Aquat. Microb. Ecol., 81, 219-241, 2018.

van Baalen, C. and Brown, R. M.: The ultrastructure of the marine blue green alga, Trichodesmium erythraeum, with special reference to the cell wall, gas vacuoles, and cylindrical bodies, Arch. Mikrobiol., 69, 79-91, https://doi.org/10.1007/BF00408566, 1969.

Villareal, T. A. and Carpenter, E. J.: Buoyancy Regulation and the Potential for Vertical Migration in the Oceanic Cyanobacterium Trichodesmium, Microb. Ecol., 45, 1-10, 2003.
Wang, M. and Shi, W.: Estimation of ocean contribution at the MODIS near-infrared wavelengths along the east coast of the U.S.: Two case studies, Geophys. Res. Lett., 32, L13606, https://doi.org/10.1029/2005GL022917, 2005.

Wang, M. and Shi, W.: The NIR-SWIR combined atmospheric correction approach for MODIS ocean color data processing, Opt. Exp., 15, 15722, https://doi.org/10.1364/OE.15.015722, 2007.

Westberry, T. K., Siegel, D. A., and Subramaniam, A.: An improved bio-optical model for the remote sensing of Trichodesmium spp. blooms, J. Geophys. Res.-Oceans, 110, 1-11, 2005. 